\title{
DETERMINANTS OF HOME GARDENING PARTICIPATION AMONG RURAL HOUSEHOLDS: EVIDENCE FROM INGQUZA HILL LOCAL MUNICIPALITY, SOUTH AFRICA
}

\author{
Yanga Nontu ${ }^{1 \bowtie}$, Amon Taruvinga ${ }^{1}$ \\ ${ }^{1}$ University of Fort Hare, South Africa
}

\begin{abstract}
The participation of rural households in home garden production, which is a premise of income and food security, is very low. Therefore, this study investigated factors influencing rural households' participation in home gardens from Ingquza Hill Local Municipality, South Africa. This is against a background where literature and development circles suggest that household home gardens can significantly improve food security and household income. Despite the fact that home gardens are a source of income and food security, rural households' participation is claimed to be very low, suggesting several factors worth explaining. The study used cross-sectional survey data from rural communities of the Eastern Cape Province, South Africa $(n=200)$, to estimate participation drivers. The initial sample was stratified into two groups; home gardeners and non-home gardeners. For home gardening participants, a census was carried out due to their limited numbers. For non-participants, convenience and purposive sampling was used focusing on households with similar socioeconomic characteristics and close to participants for pairing purposes. Using stratified purposive convenience sampling, two homogeneous mutually exclusive strata were created (stratum "A"; "HGs participants": $n=87$ and stratum "B"; "HGs non-participants": $n=113$ ) for an independent analysis. Binary logistic regression analysis was used to analyze the data. Regression results revealed that home garden participation was influenced by gender, education, household income, extension services, access to arable land, and credit access. This paper concluded that education, household income, access to extension services, and access to arable land were the major factors capable of positively influencing household participation in home gardening. In contrast, gender and access to
\end{abstract}

credit were negatively associated with household participation in home gardening. Therefore, the paper calls for government policies and intervention programs targeting home gardening to improve rural household participation in home gardens.

Keywords: home gardens, binary logistic regression, participation, O.R. Tambo District Municipality, Ingquza Hill Local Municipality

\section{INTRODUCTION}

Home gardens $(\mathrm{HG})$ originate or are allocated in rural and urban areas, mostly in small agricultural land systems (Nair, 1993). Generally, home gardening refers to the cultivation of a small portion of land around the household or within walking distance from the family home (Odebode, 2006). Niñez (1984) defined home garden as a small-scale production system supplying plant and animal consumption and utilitarian items either not obtainable, affordable, or readily available through retail markets, field cultivation, hunting, gathering, fishing, and wage-earning. Home gardening is already very common in most poor households in rural areas; however, the practices are not on a large scale and therefore do not offer adequate products for all-year-round nutrition. Home gardening is classified into three categories: "traditional", "improved," and "developed" (Talukder et al.,

\footnotetext{
$\bowtie$ Yanga Nontu, Department of Agricultural Economics and Extension, University of Fort Hare, South Africa, e-mail: nontuyanga @gmail.com, https://orcid.org/0000-0003-4843-9437
} 
2008). Traditional gardens are maintained on scattered plots, seasonal and with a few conventional fruits and vegetables such as pumpkins. Improved gardens produce more varieties of fruits and vegetables than traditional gardens but only during certain times of the year and are maintained on fixed plots. Developed gardens produce a wide variety of fruits and vegetables available throughout the year and are kept on selected fields (Talukder et al., 2008).

According to Galhena e al. (2012), home gardens by nature require different activities depending on the ecological region of allocation, land availability, and household labor. Each home garden has a unique composition in terms of structure, appearance, functionality, and productivity (Niñez, 1984; Fernandes and Nair 1986; Torquebiau, 1992). They depend on the natural ecology of the location, available family resources such as labor, and skills, preferences, and enthusiasm of family members (Galhena et al., 2013). Thus far, home garden cultivation tends to be quite dynamic (Eyzaguirre and Linares, 2010). Decisions related to the selection of crops, procuring inputs, harvesting, management, and so forth are driven mainly by households' consumption and income generation needs (Galhena et al., 2013).

StatsSA (2011) highlights that Ingquza Hill Local Municipality is dominated by a high poverty rate and low agricultural practice. Against this background, multiple strategies are required to address the issue of food production and food security (Bhandari et al., 2016). It is evident from the literature that home gardens are a part of the agriculture and food production systems in many developing countries and are widely used as a remedy to alleviate hunger and malnutrition in the face of a global food crisis (van Lier, 2017; Uzokwe et al., 2016; FAO, 2015). Furthermore, several studies have documented home gardens as an essential supplemental source contributing to food and nutritional security, livelihoods, and income generation in rural areas (Reddiar and Reddiar, 2016; Walsh and Van Rooyen, 2015). On the contrary, several studies (Masset et al., 2012; Webb, 2013) also question the food and nutritional security contributions of home gardens at the level of households in rural areas. Therefore, the actual contribution of home gardens to household food and nutritional security remains a highly debated issue worth probing in different geopolitical environments.

This study was motivated by the low proportion of home gardening in rural areas (FAO, 2015), especially in the rural areas of Ingquza Hill Local Municipality where food and nutritional insecurity is critical (StatsSA, 2011), even though home gardening is claimed to address food and nutritional security challenges (Chauhan, 2015). The paper, therefore, examined factors influencing the participation of rural households in home gardening.

\section{MATERIAL AND METHODS}

\section{Study area}

Ingquza Hill Local Municipality is one of five local municipalities that fall within the O. R. Tambo District Municipality of the Eastern Cape Province. Ingquza Hill is located to the northwest of the OR Tambo District with the coordinates $32^{\circ} 10^{\prime} \mathrm{S} 28^{\circ} 35^{\prime} \mathrm{E}$. The Municipality seat is in Flagstaff and the municipal area is divided into 31 wards (Stats SA, 2008). It covers 2,477 square kilometers (956 square miles) of the municipality's total area (StatsSA, 2008). Ingquza Hill local municipality has an estimated total population of approximately 278481 (StatsSA, 2008). Flagstaff town is part of Ingquza Hill local municipality of OR Tambo District. Flagstaff is located to the north-east of Umtata, in the former Pondoland.

\section{Data and empirical model used}

The study used a cross-sectional field survey. Data was gathered from 200 households using the availability sampling method from four randomly selected villages: Sipaqeni, Mhlanga, Bhalasi, and Msikaba of Ingquza Hill Local Municipality. Two hundred households were selected for direct questioning from the entire sampling frame, using the "in-person interview" approach. The initial sample was stratified into two groups; home gardeners and non-gardeners. For home gardening participants, a census was carried out due to their limited numbers. For non-participants, purposive and convenience sampling was used focusing on households with socioeconomic characteristics almost similar and close to participants for pairing purposes. Using stratified purposive and convenience sampling, two homogeneous mutually exclusive strata were created (stratum "A"; "HGs participants": $n=87$ and stratum "B"; "HGs non-participants": $n=113$ ) for an independent analysis. Table 1 below presents a summary of the sampling units $\mathrm{A}$ and $\mathrm{B}$. 
Table 1. The distribution of respondents with respect to home garden status

\begin{tabular}{lccc}
\hline Study Area & Participants & Non-participants & Total \\
\hline Flagstaff & 87 & 113 & 200 \\
Total & 87 & 113 & 200 \\
\hline
\end{tabular}

Source: own elaboration.

A total of two hundred households were selected from the study area, comprising of eighty-seven participants and one hundred and thirteen non-participants.

Binary logistic regression was used to analyze the factors influencing households' participation in home gardening. The model was specified as illustrated in equation 1 that daws on (Malahlela, 2015).

$$
\begin{gathered}
\operatorname{Logit}(P i)=\ln (P i / 1-\mathrm{Pi})=\alpha+\beta_{1} X_{1}+ \\
\ldots \ldots \ldots+\beta_{\mathrm{n}} X_{\mathrm{n}}+\mu_{1}
\end{gathered}
$$

where: $\log [(P i /(1-P i)]-$ is logit for home gardening participation choice; $P i$ - is predicted probability that $Y$ equals one (Home Gardening participants); 1 $P i$ - is predicted probability that $Y$ equals zero (Home Gardening non-participants); $\alpha$ - intercept term or the constant of the equation; $\beta$ - estimated parameters or the coefficient of the independent variables; $X$ - independent variables; $\mu_{1}$ - the error term.

The specific model is given as illustrated in equation 2 :

$$
\begin{gathered}
\ln (P(Y=1 / X)) /(1-P(Y=1 / X))= \\
\alpha+\beta_{1} X_{1}+\beta_{2} X_{2}+\beta_{3} X_{3}+\mu_{1}
\end{gathered}
$$

\section{RESULTS AND DISCUSSION}

\section{Basic sample statistics}

This section presents the basic sample statistics of home gardeners and non- gardeners. Table 1 below represents a summary of the sample statistics from the area of study. A sample of 200 participants was selected from the study area, with a mean household head age of 59. The mean education level was 1.98 , which means that participants were educated up to the primary level on average. The basic sample statistics suggest that the considered sample had more females than males, with an average monthly income of R3151.63. The basic sample results show an average household size of 6 family members, with a minimum of 1 and a maximum of 12 family members. A majority of the respondents did not have access to market, membership in community-based organizations (CBOs) or access to credits. The asymmetry of distribution was both positively and negatively skewed, as shown in Table 1 below. Most of

Table 1. Basic sample statistics of the respondents

\begin{tabular}{lrrrrrr}
\hline \multicolumn{1}{c}{ Variables } & Valid & Mean & Std. Deviation & Skewness & Minimum & Maximum \\
\hline Gender & 200 & 0.77 & 0.422 & -1.293 & 0 & 1 \\
Age & 200 & 58.48 & 12.651 & -0.608 & 27 & 84 \\
Household size & 200 & 5.63 & 2.369 & -0.182 & 0 & 12 \\
Education level & 200 & 1.98 & 1.147 & 0.685 & 1 & 4 \\
Total household income & 200 & 3151.63 & 2865.708 & 2.776 & 0 & 19000 \\
Distance to market & 200 & 0.66 & 0.477 & -0.657 & 0 & 1 \\
Availability of ext. services & 200 & 0.60 & 0.492 & -0.390 & 0 & 1 \\
Member of CBOs & 200 & 0.39 & 0.488 & 0.476 & 0 & 1 \\
Access to a land & 200 & 0.87 & 0.337 & -2.217 & 0 & 1 \\
Market access & 200 & 0.43 & 0.496 & 0.306 & 0 & 1 \\
Access to credit & 200 & 0.40 & 0.491 & 0.411 & 0 & 1 \\
\hline
\end{tabular}

Source: own elaboration. 
the characteristics had skewness values below and close to 1 (except for household income and access to land); this suggests that the distribution did not differ significantly from normal symmetric distribution.

\section{Factors that influence participation in home gardens}

Several demographic, socioeconomic and institutional variables, which are believed to influence the decision to participate in home garden activities, were included in the binary logistic regression model as summarised in Table 2 . From the eleven predictor variables fitted in the binary logistic regression model, six variables significantly impacted households' participation in home gardening, while five had no significant effect. Of the six significant predictor variables, four predictor variables (education level, household income, access to extension and access to arable land) had a positive sign, implying an increase in these variables would be associated with an increase in households' participation level in home gardening and the other two predictor variables (gender and access to credit) had negative signs; meaning an increase in either of these variables would be associated with a decrease in participation level as shown in Table 1. With regard to model fit, the Lemeshow Goodness-of-Fit test statistics was 1.00 implying that the model's estimates fit the data at an acceptable level. Pseudo $\mathrm{R}^{2}$ was computed as a proxy estimate to $\mathrm{R}^{2}$ in OLS regression which,

Table 2. Determinants of participation in home gardens

\begin{tabular}{ccccc}
\hline Independent variables & $\beta$ & B & S.E. & Sig. \\
\hline Constant & $\beta_{0}$ & -2.247 & 1.157 & $0.052^{*}$
\end{tabular}

Socioeconomic factors

\begin{tabular}{|c|c|c|c|c|c|}
\hline a) & Gender & $\beta_{1}$ & -1.795 & 0.546 & $0.001 * *$ \\
\hline b) & Age & $\beta_{2}$ & 0.005 & 0.016 & 0.760 \\
\hline c) & Household size & $\beta_{3}$ & 0.059 & 0.081 & 0.468 \\
\hline d) & Education level & $\beta_{4}$ & & & $0.089 *$ \\
\hline (a) & Education (primary) & $\beta_{4 a}$ & 1.368 & 0.580 & $0.018^{*}$ \\
\hline (b) & Education (secondary) & $\beta_{4 b}$ & 1.618 & 0.691 & $0.019 *$ \\
\hline e) & Household income & $\beta_{5}$ & 0.000 & 0.000 & $0.013 *$ \\
\hline \multicolumn{6}{|c|}{ Institutional factors } \\
\hline a) & Market place & $\beta_{6}$ & 0.371 & 0.335 & 0.268 \\
\hline b) & Distance to market & $\beta_{7}$ & 0.404 & 0.366 & 0.270 \\
\hline c) & Ex. Services & $\beta_{8}$ & 0.577 & 0.350 & $0.099 *$ \\
\hline d) & Market access & $\beta_{9}$ & -0.319 & 0.348 & 0.360 \\
\hline e) & Access to arable land & $\beta_{10}$ & 1.805 & 0.527 & $0.001 * *$ \\
\hline f) & Access to credit & $\beta_{11}$ & -1.127 & 0.348 & $0.001 * *$ \\
\hline g) & Member of COBs & $\beta_{12}$ & 0.163 & 0.356 & 0.647 \\
\hline \multicolumn{6}{|c|}{ Model summary } \\
\hline \multicolumn{5}{|c|}{ Chi-square $(\mathrm{df}=13)$} & 51.257 \\
\hline \multicolumn{5}{|c|}{$(-2) \log$ likelihood } & 217.947 \\
\hline \multicolumn{5}{|c|}{ Nagelkerke's $R^{2}$} & 0.306 \\
\hline
\end{tabular}

$* * *, * *$ and $*$ indicates significance at the probability level of $0.01,0.05$ and 0.1 , respectively. 
according to Norusis (2004), measures the proportion of the variation in the response explained by the model. In this study, Nagelkerke's $R^{2}$ of 0.306 was obtained; this indicates that not much of the model's variation was explained, as shown in Table 2.

Gender: Regarding gender, results indicate a significant negative association between gender and participation in home gardening, as summarised in Table 2 above. Per every positive standard deviation change in the gender of a household head, the results reveal a 1.795 decrease in the log odds of participation in home gardens, holding other independent variables constant. The observed results suggest that male-headed households have a higher probability of participating in home gardening than their female counterparts. These findings, however, contradict previous studies by Patalagsa et al. (2015) who notes that home gardening activities in most rural areas have become a domain of women, mainly because the majority of men are more involved in nonagricultural activities, such as manufacturing, mining, brick making, and car repairs. The dominance of maize production $(40 \%)$ in home gardens from the study area explains the negative association where male household heads would be expected to participate more in home gardens than their female counterparts. These farmers mainly produced yellow maize normally used for stock feed and cash sales. Since most male-headed households target cash crops and cattle production, as Mmbengeni and Makoka (2002) suggested, the observed association may be explained by the dominance of yellow maize production (a cash and stock feed crop) in home gardens.

Education level: The coefficients of education level were statistically significant and positively associated with home gardening participation, as summarized in Table 2. For every unit of increase in household head education, results reveal a 0.089 increase in the log odds of the involvement in home gardens holding other independent variables constant. These results further suggest that as the household head's education increases, participation in home gardens increases. Educational attainment by the household head could lead to awareness of the possible advantages of home gardening (subsistence agricultural practices) as suggested by Najafi (2003) and an improved level of awareness of nutritional health benefits of home gardens (Gbedomon et al., 2015).

Household income: The model results indicate a positive association between household income and participation in home gardening. These results suggest that as income increases, participation in home gardening increases too. These findings suggest that household income finances home gardening through the purchase of production inputs (seed, fertilizer, irrigation, pesticides) and initial establishment costs (fencing and land preparation). Therefore, public policies and investments that improve household income may be targeted to promote home gardening.

Access to extension services: The model results also indicate a positive association between access to extension services and participation in home gardening. For every unit of increase in access to extension services, a 0.577 increase in the log odds of participation in home gardens was confirmed holding other independent variables constant, as shown in Table 2. These findings indicate that households with access to extension services have a high probability of participation in home gardening. This might be explained by the fact that extension contact with farmers enhances the acquisition of new knowledge, skills, and practices on improved technology by the farmers as well as their innovativeness, which is expected to translate into increased participation in home gardening. These findings support previous studies, highlighting that access to extension services has a positive association with participation in home gardening because of the availability of information to households that can boost their confidence and influence their decision to participate in home gardening (Yong, 2014).

Access to arable land: Access to arable land was statistically significant and positively related to participation in home gardening. For every unit of increase in access to arable land, a 1.805 increase in the log odds of participation in home gardening by households, holding all other independent variables constant, was confirmed. These findings suggest that households with access to arable land have a high probability of participating in home gardening. These findings are in line with the findings by Mdoda (2014) who notes a positive relationship between land ownership and participation in agricultural activities, mainly because land ownership encourages households to participate in cropping activities, contributing to their livelihoods. Therefore, lack of arable land may be a barrier to home gardening and participation is encouraged.

Access to credit: The variable access to credit was statistically significant and negatively related to home gardening participation. For every unit of increase in 
access to credit, a 1.127 decrease in the log odds of participation in home gardening by households, holding all other independent variables constant, was confirmed, as shown in Table 2 above. These results suggest that as smallholder farmers increase their access to credit, their participation in home gardening decreases. This may be explained by the fact that access to credit promotes investments in high-return enterprises such as field cash crops capable of paying back the borrowed capital plus interest rather than investments in home gardening where production is for local consumption and sale of surplus. This, therefore, suggests that access to credit may discourage a smallholder farmer's decision to participate in home gardening because home gardening activities may fail to generate enough cash to pay back the borrowed capital.

\section{CONCLUSION AND RECOMMENDATIONS}

This paper concludes that level of education, household income, access to extension services and access to arable land were the major factors positively influencing household participation in home gardening, while gender and access to credit were negatively associated with home garden participation.

The results of this study, therefore, suggest that to promote farmers' participation in home gardens in rural areas, the following variables may be targeted:

(i) Education - results revealed a positive influence of education on home garden participation; thus, targeted informal education through community-based organizations may raise rural communities' awareness of home garden benefits, which may trigger participation.

(ii) Gender - results revealed that male-headed households were more likely to participate in home gardens than their female counterparts. Therefore, this calls for more studies to understand gender-based barriers to participation in home gardens and target awareness campaigns to encourage women's participation in home gardens.

(iii) Household income - results revealed a positive influence of household income on home garden participation. Therefore, public policies, rural development programs, and activities that increase household income may be targeted to promote participation in home gardens. (iv) Access to extension services - the model results revealed the power of extension visibility in promoting participation as farmers share benefits, production, and market information. In this respect, strategies that improve rural households - extension office contact (extension applications for mobile phones) may go a long way towards promoting participation in home gardening.

(v) Access to arable land - participation in home gardening is also driven by the availability of arable land. Thus, public policies and rural investment programs that make arable land available to rural communities (land redistribution) are more likely to increase and encourage households' participation in home gardening.

\section{ACKNOWLEDGEMENTS}

The authors wish to acknowledge Ada and Bertie Levenstein Bursary and the National Research Foundation (NRF) for financial support.

\section{REFERENCES}

Abdoellah, O.S., Hadikusumah, H.Y., Takeuchi, K., Okubo, S., Parikesit (2006). Commercialization of home gardens in an Indonesian village: vegetation composition and functional changes. Agroforest. Syst., 68, 1-13.

Bhandari, S., Sayami, J.T., Thapa, P., Sayami, M., Kandel, B.P., Banjara, M.R. (2016). Dietary intake patterns and nutritional status of women of reproductive age in Nepal: Findings from a health survey. Arch. Pub. Health., 74(1), $1-11$.

Chauhan, R. (2015). An investigation of the relationships among home gardens, dietary diversity, and the nutritional status of children aged 0 to 5 in Indian households. Unpublished Masters Thesis, University of Illinois at Urbana-Champaign, United States of America.

DAFF (Department of Agriculture, Forestry and Fisheries). (2014). Directorate: Food Security, Strategic outlook.

Eyzaguirre, P.B., Linares, O.F. (2010). Introduction in Home gardens and Agro-biodiversity. Eds. Washington DC, USA: Smithsonian Books.

FAO (Food and Agriculture Organization). (2015). Guidelines for measuring household and individual dietary diversity. Rome, Italy: Food and Agriculture Organization of the United Nations.

Fernandes, E.C.M., Nair, P.K.R. (1986). An evaluation of the structure and function of tropical home gardens. Agric. Syst., 21, 279-310. 
Nontu, Y., Taruvinga, A. (2021). Determinants of home gardening participation among rural households: evidence from Ingquza Hill Local Municipality, South Africa. J. Agribus. Rural Dev., 2(60), 213-220. http://dx.doi.org/10.17306/J.JARD.2021.01402

Galhena, D.H., Freed, R., Maredia, K.M. (2013). Home gardens: a promising approach to enhance household food security and wellbeing. Agric. Food Sec., 2(1), 8.

Galhena, D.H., Mikunthan, G., Maredia, K.M. (2012). Home Gardens for Enhancing Food Security in Sri Lanka. Farm. Matt., 28(2), 12

Gbedomon, R.C., Fandohan, A.B., Salako, V.K., Idohou, A.F.R., Kakaï, R.G., Assogbadjo, A.E. (2015). Factors affecting home gardens ownership, diversity and structure: a case study from Benin. J. Ethnobiol. Ethnomed. Retrieved May $12^{\text {th }} 2018$ from: 10.1186/s13002-015-0041-3.

Gomes, F.D.S.E., Silva, G.A., Ribeiro De Castro, I.R. (2017). Effect of home vegetable gardening on the household availability of fruits and vegetables. Rev. Nutr., 30(2), 245-260.

Gupta, A.K. (1989). Scientists' views of farmers' practices in India: barriers to effective interaction. In: R. Chambers, A. Pacey, L.A. Thrupp (1989). Farmer First. Farmer Innovation and Agricultural Research. London: Intermediate Technology Publications.

Hoogerbrugge, I., Fresco, L.O. (1993). Homegarden Systems: Agricultural Characteristics and Challenges. London: International Institute for Environment and Development.

Malahlela, N.D. (2015). Socioeconomic Contribution of Community Food Gardens to the Livelihoods of rural households in Lepelle-Nkumpi Local Municipality of Limpopo Province. Unpublished Masters thesis, University of Fort Hare, Eastern Cape, South Africa.

Masset, E., Haddad, L., Cornelius, A., Isaza-Castro, J. (2012). Effectiveness of agricultural interventions that aim to improve nutritional status of children: systematic review. Brit. Med. J., 344, d8222.

Mdoda, L. (2014). Farmers' awareness of climate change and variability and its effects on agricultural productivity: The case of King Sabata Dalindyebo Municipality in Eastern Cape. Alice: Unpublished Master's thesis, University of Fort Hare, Eastern Cape, South Africa.

Mmbengeni, M.E., Makoka, M.S. (2002). Provincial report on education and training for Agriculture and rural development in Limpopo Province. Polokwane, South Africa. Limpopo Department of Agriculture.

Nair, P.K.R. (1993). An Introduction to Agroforestry. Dordrecht: Kluwer Academic Publishers. Retrieved June $5^{\text {th }} 2018$ from: https://hdl.handle.net/10568/45199

Najafi, B. (2003). An overview of current land utilization systems and their contribution to agricultural productivity, Report of the APO Seminar on impact of land utilization systems on agricultural productivity. Productivity Organization, Islamic Republic of Iran Asian.

Niñez, V.K. (1984). Household Gardens: Theoretical Considerations on an Old Survival Strategy. Peru, Lima: International Potato Center.
Norusis, M.J. (2004). SPSS 13.0 advanced statistical procedures companion. Englewood Cliffs: Prentice Hall.

Odebode, O.S. (2006). Assessment of home gardening as a potential source of household income in Akinyele Local Government Area of Oyo State. Nig. J. Hort. Sci., 2, 47-55.

Osei, A., Pandey, P., Nielsen, J., Pries, A., Spiro, D., Davis, D., Quinn, V., Haselow, N. (2017). Combining Home Garden, Poultry, and Nutrition Education Program Targeted to Families with Young Children Improved Anemia among Children and Anemia and Underweight among Nonpregnant Women in Nepal. Food Nutr. Bull., 38(1), 49-64.

Patalagsa, M.A., Schreinemachers, P., Begum, S., Begum, S. (2015). Sowing seeds of empowerment: effect of women's home garden training in Bangladesh. Agric. Food Sec., 4(1), 24

Perrault-Archambault, M., Coomes, O.T. (2008). Distribution of agrobiodiversity in home gardens along the Corrientes River, Peruvian Amazon. Econ. Bot., 62(2), 109-126.

Peyre, A., Guidal, A., Wiersum, K.F., Bongers, F. (2006). Dynamics of home garden structure and functions in Kerala, India. Agroforest. Syst., 66, 101-115.

Reddiar, K.L., Reddiar, S.K. (2016). 'Family agriculture for bottom-up rural development: a case study of the indigenous Mayan population in the Mexican Peninsula. Future of Food. J. Food Agric. Soc., 4(1), 29-39.

StatsSA (Statistics South Africa). (2008). Population estimates 2009. Pretoria, South Africa. Retrieved Dec $27^{\text {th }}$ 2017 from: www.statssa.gov.za/publications/P0302/ P03022009.pdf

StatsSA (Statistics South Africa). (2011). Statistical release.

Talukder, A., De pee, S., Bloem, M.W. (2008). Homestead food production for improving nutritional status and health. In: R.D. Semba, M.W. Bloem (Eds.), Nutrition and Health in Developing Countries. Totowa, NJ: Humana Press.

Torquebiau, E. (1992). Are tropical agroforestry gardens sustainable? Agric. Ecosys. Env., 41, 189-207

Uzokwe, U.N., Giweze, E.A., Ofuoku, A.U. (2016). Contribution of home gardening to family food security in Delta North Agricultural Zone, Delta State, Nigeria. Int. J. Agric. Ext. Rural Dev. Stud., 3(2), 26-33.

van Lier, L.E. (2017). Home Gardening and the Health and Well-Being of Adolescents. Health Prom. Pract,. 18(1), 34-43.

Walsh, C.M., Van Rooyen, F.C. (2015). 'Household food security and hunger in rural and urban communities in the Free State Province, South Africa. Eco. Food Nutr., 54(2), $118-137$.

Webb, P. (2013). Impact pathways from agricultural research to improved nutrition and health: literature analysis and 
Nontu, Y., Taruvinga, A. (2021). Determinants of home gardening participation among rural households: evidence from Ingquza Hill Local Municipality, South Africa. J. Agribus. Rural Dev., 2(60), 213-220. http://dx.doi.org/10.17306/J.JARD.2021.01402

research priorities. Rome - Geneva: Food and Agriculture Organization and World Health Organization.

Wiersum, K.F. (2006). Diversity and change in home garden cultivation in Indonesia. In: B.M. Kumar, P.K.R. Nair (Eds.). (2006). Tropical homegardens: a time-tested example of sustainable agroforestry. Dordrecht, the Netherlands, Springer Science 13-24.
Yong, D.G. (2014). Factors Affecting the Choice of Adaptation Measures to Climate Change: The Case of Famers in the Sudano-Sahelioan Area of Cameroon. Tanz. Econ. Rev., (4)1, 56-72. 